\title{
An Overview of Warehouse Optimization
}

\author{
Jan Karásek
}

\begin{abstract}
This paper presents an overview related to warehouse optimization problems. The problems are divided in to several groups. First, the basic technical structure of warehouse is described. Second, the standard operational and organizational framework of warehousing company is characterized, which is in special attention in this work. Third, the coordinating and controlling systems for warehouse operations is briefly mentioned, and typical warehousing operations dependent on technical and operational structure are described. The main contribution of this paper is to show the current state of the art in optimization in mentioned three groups of interest in logistic warehouses and distribution centers.
\end{abstract}

Keywords-Logistics, Optimization, Warehouse.

\section{INTRODUCTION}

Modern logistic warehouses and distributions centers are designed on the basis of dozens optimization studies. In consequence of that, Warehouse Management Systems (WMS) become important and more complex and users find it quite hard to manage. The software market offers large variety of solutions with different system requirements and possibilities, and to choose the suitable system for every company is not quite an easy task, because it is influenced by many aspects which must be considered, and one of this aspects are optimization methods based on automated processes for tasks dynamically changeable in time. The WMSs which drive logistic warehouses and distribution centers are core elements of the material and goods flow in logistic chain and they will be subjected to further investigation in following text related to optimization of technical and operational structure.

According to the [1] the activities of the warehousing optimization can be divided into three groups. First, the basic technical structure of warehouse. Second, the operational and organizational framework, to which a special attention is paid in this work. Third, the coordinating and controlling systems for warehouse operations. The main contribution of this paper is to show the current state-of-the-art in optimization in mentioned three groups of interest, and to help researchers with orientation in logistic warehouse optimization problems.

The rest of the paper is organized as follows. The second section gives an overview of optimization related to technical structure of logistic warehouses and distribution centers. The third section is related to optimization of operational structure. The fourth section very briefly describes the WMSs which are the core of every warehouse. The fifth section describes the typical warehousing operations which are tightly related to optimization of technical and operational structure of warehouses. The last section gives a conclusion of the paper.

Jan Karásek is with the Department of Telecommunications, Faculty of Electrical Engineering and Communication, Brno University of Technology, Technická 12, 61600 Brno, Czech Republic, e-mail: karasekj@feec.vutbr.cz. Manuscript received October 21, 2013; revised October 31, 2013.

\section{Optimization of Technical Structure}

The basic technical structure involves e.g. the layout design of the logistic warehouse or whole distribution center, the choice and dimensioning of conveyors and warehouse equipment, the design of the physical interfaces to neighboring systems and other attributes related to technical structure.

Example of Warehouse with Traditional Layout 2

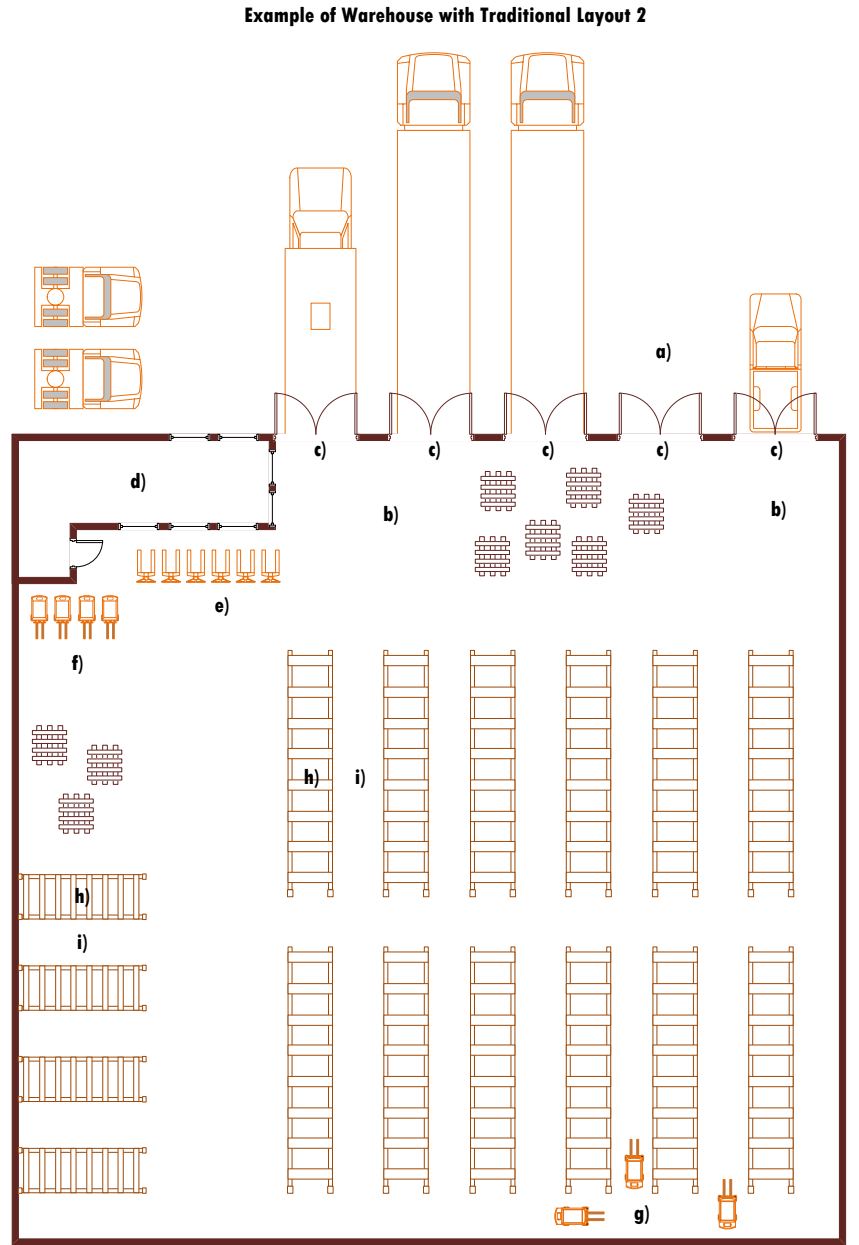

Fig. 1. The Example of Traditional Rectangular Warehouse Layout

The layout design of the warehouse [2] is a key component of further optimization tasks and has a significant impact on order-picking and traveling distances in the warehouse. In [3] it was found out that the layout design has more than $60 \%$ effect on the total travel distance, and three basic types of warehouse layout were presented. In [4] and [5], the application of parallel cross aisles in the warehouse was presented, and it was considered as a significant improvement. The layout is usually of rectangular shape and based on pallet manipulation [6], see Fig. 1] According to [7] and [8] there is 
a few factors to be considered in the layout design, such as: the number of blocks; the length, the width, and the number of picking aisles; the number and shape of cross aisles if they are present; the number of rack levels; and the position of input and output gates in the warehouse. In [9] has been presented a new Flying-V and Fishbone design of cross aisles, which offers a $10 \%-20 \%$ reduction of traveling distance. In [10] has been introduced an analysis of dual-commands and in [11] has been introduced adapted Fishbone design for dual-commands. In dual-commands environment the worker loads the goods in a pickup and deposit location and travels to a storage location and then travels to another location from which he picks goods and returns back. In [12] has been proposed a more developed Flying- $V$ design of cross aisle and Inverted- $V$ design. This improvement brings another $3 \%$ saving of traveling distance. The warehouse layout is also connected with the aisle design [13], [14]. The layout is mostly narrow-aisle-like, which increases the space utilization with minimal costs, but it can lead to higher operational costs and more congestions among workers.
Traditional Layout 1

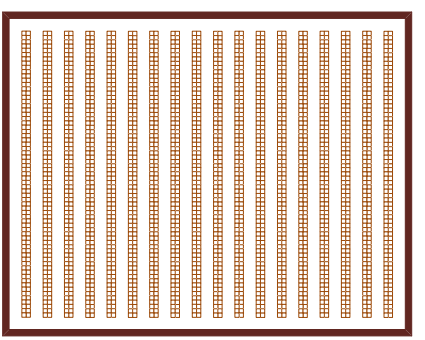

Traditional Layout 2

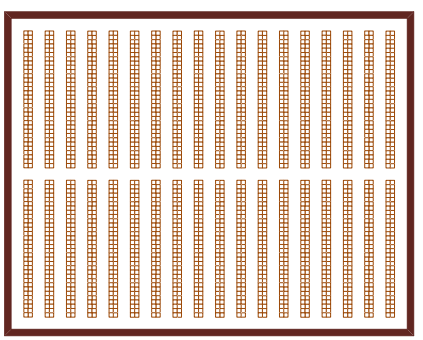

Traditional Layout 3

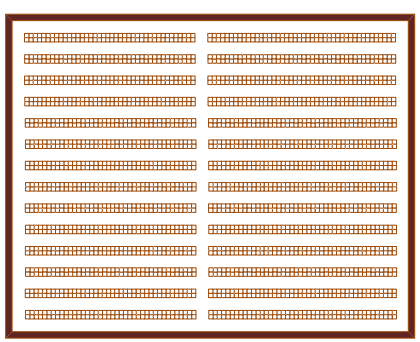

Flying-V Layout

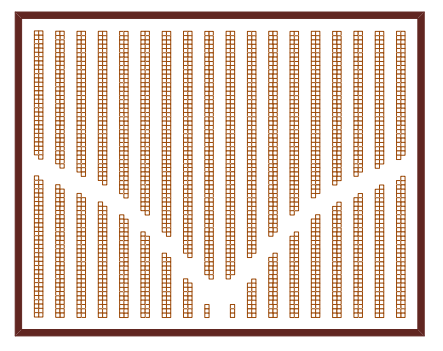

Fishbone Layout

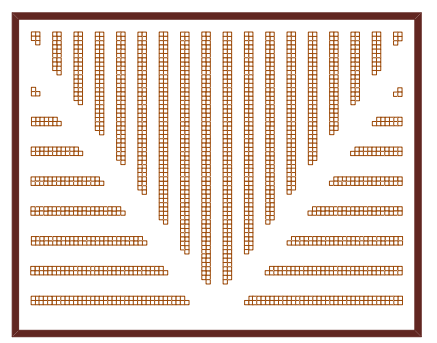

Inverted-V Layout

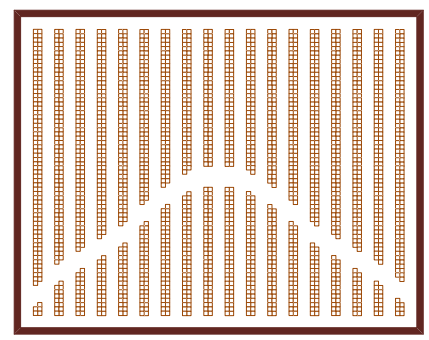

Fig. 2. The Warehouse Layout Examples, see [9] and [12]

There are many types of warehouse equipment, especially the equipment which should reduce labor cost and increase its utilization. Common storage models cover pallet racks, cartoon flow racks for high-volume picking, and shelving for lower-volume picking. All this equipment is standardized according to the dimensions, but the standardization is mostly only for a specific continent. While pallet manipulation is demanded in all types of warehouses, conveyors are not used everywhere. Conveyors divide the warehouse into zones, move a material through a given path, and also restricts the movement of workers and saves their energy. With the deployment of conveyors the sortation system is quite often installed. Sortation is mostly based on some scanning technology of Bar-Codes, RFID chips, Magnetic strips or Machine vision. The system works on a few common principles, e.g. push sorter pushes a passing carton to alternative path from the main conveyor, tilt-tray sorter works on the principle of tilting a tray and the object slides into the collecting bin, and others. Cranes are used to move materials over a variable paths in restricted area, e.g. jib crane, bridge crane, gantry crane, and stacker crane. Positioning equipment is used to handle material at a single location, e.g. hoists, balancers, and other manipulators. The automation in this area often covers systems such as Carousels, A-frames, and Automated Storage and Retrieval System (ASRS).

Carousel is a shelf rotating in the circle. Instead of the picker traveling, the storage location is moving. A simple rotation pattern on how to quickly find the shortest way to pick the order was introduced in [15] and [16]. Large orders in carousel environment have been studied in [17]. The carousels with multiple order-picking have been studied in [18]. Optimal storage locations have been investigated in [19]. An A-frame is an automated dispensing machine dropping items onto a conveyor. A-frame is used when a product is picked in very high volumes, the labor is expensive and is used only to refill A-frames. In-aisle cranes, so called ASRSs, replace the humans using trucks with simple robotic devices, moving in horizontal and vertical direction in the full extent of aisle. The design and performance of such models as well as travel time models have been investigated in [20], [21], [22], and [23]. Despite of all these inventions, the typical model of warehouse with pickers and various models of trucks are still quite popular. Other design and performance models are described in [24], [25], [26].

\section{Optimization OF Operational StRUCTURE}

The operational and organizational framework combines different aspects from many areas, e.g. business management, inventory management, organization management, transportation management and many other areas of management. There are two basic slotting strategies (storing assignment policies [27]): random and dedicated. While random strategy allows to store a pallet on an arbitrary empty location with the same probability [28] or on the closest empty location [7], the dedicated strategy allows to store a pallet only on specified locations. The storage locations are often organized somehow. The organization can be e.g. class-based storage, where the goods are clustered according to the frequency of orders. This policy assigns the most frequently requested goods to the best (closest) locations from input/output gates. Another possibility is to use family grouping, where the goods are clustered according to relations or similarities between products or orders [29], [30]. 

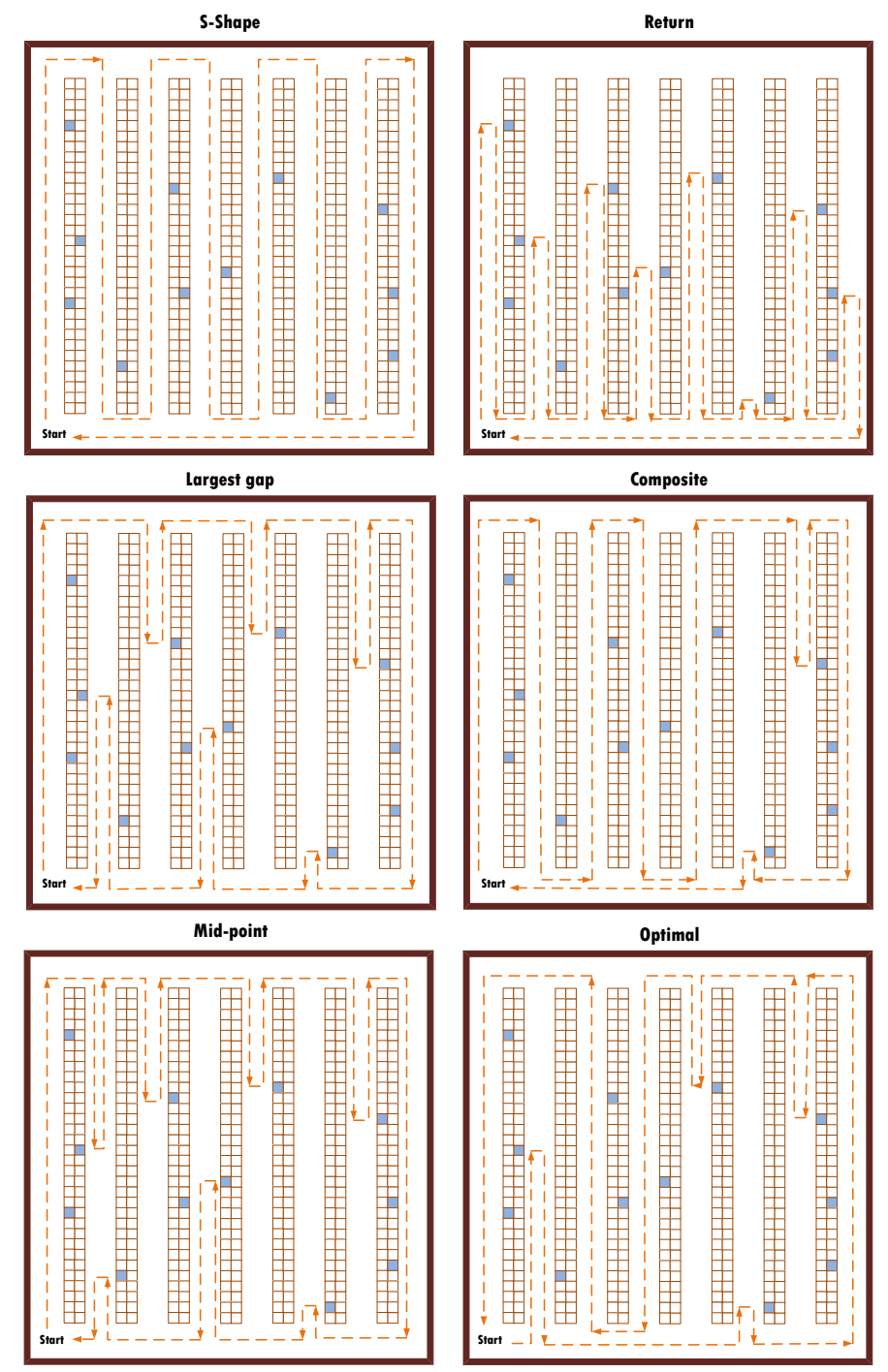

Fig. 3. The Common Routing Methods described in [5]

Single order-picking is the strategy where pickers pick only one order at a time and it is one of the most used picking policies. A Stock Keeping Unit (SKU) is tightly related to order-picking. SKU represents the smallest physical unit of a product with which a company manipulates, e.g. a box, a kind of case or carton consisting of inner packs and individual pieces of product, but it can also be only a pallet in huge distribution centers.

The routing policies should ensure an optimal travel path through the warehouse for order-picking. One of the first algorithms for optimal order-picking path design was introduced in [31]. Since the algorithm can be applied only for conventional warehouses, the problem is mostly solved by heuristic methods. The common routing methods, see Fig. 3. described in [5] are: S-shape, Return policy, Mid-point strategy, Largest gap strategy, Composite heuristic, Optimal routing. All the methods were primarily developed for singleblock warehouses. Modified methods for multiple-block warehouses were proposed in [4].
If the order is small and is far from exceeding the picking capacity, it is possible to pick more orders in a single orderpicking tour. This is known in the literature as order batching or simply batching. Since this is a job with sub-tasks (a picking tour with several orders) it is considered a NP-hard problem. It was proved in [32] that batching has a significant impact on the performance of order-picking. Therefore, researchers pay attention to the problem of batching and the heuristic methods are still under investigation [33], [34]. It is also possible to divide an order-picking process into zones. Goods belonging to the same product group are stored in the same zone. In comparison with batching, zoning does not have a significant impact on the performance of the order-picking system [35]. The advantage of zoning lies in reducing the congestion in the aisles and when the goods are really in one small area, the traveling is also reduced. The main disadvantage is the consolidation of order when it is completed by more pickers from different zones.

\section{OPTIMIZATION OF WAREHOUSE MANAGEMENT}

The coordinating systems and control are of special importance. The WMSs are used to control and optimize the warehouse and all typical warehousing operations (see section $\mathrm{V}$, to know every detail about goods and their actual storage location all the time, the utilization of workforce, orders, and they also orchestrate the flow of people, machines, and goods. Such systems have many interfaces to adjacent systems in a company, e.g. merchandizing systems, information systems, production and enterprise resource planning systems, material flow and warehouse controlling systems and other systems related to a business-to-business or business-to-consumer.

Why is all the optimization being applied? Everything is based on customer demands. The main reasons to optimize are to increase the performance of the company regarding the demand-driven production (pull system), to ensure the productivity (based on just-in-time delivery) and minimize the stock along the supply chain, provide additional services, and reduce the transportation costs.

\section{TyPICAL WAREHOUSING OPERATIONS}

The basic processes in warehouse are receiving, storing, put-away, picking/retrieving and shipping goods. The shipping operation can also consist of many sub-tasks such as consolidation of goods if the batching, grouping or zoning is applied, checking the order according to its completeness, packing and, of course, shipping. The literature also mentions cross-docking as a special warehouse operation. The crossdocking is described at the end of this sub-section.

Receiving is the first operation in the warehouse. This process starts by notification of the arrival of goods. Then begins process of unloading, counting, identifying, quality control, and goods acceptance (incoming inspection) related to a type and quantity by unloading staff according to the company rules. When the goods are accepted, the receipt is issued. The acceptance depends on the delivery status - the delivery date, the quality of delivery, the planned schedule which should also minimize a truck waiting time. 


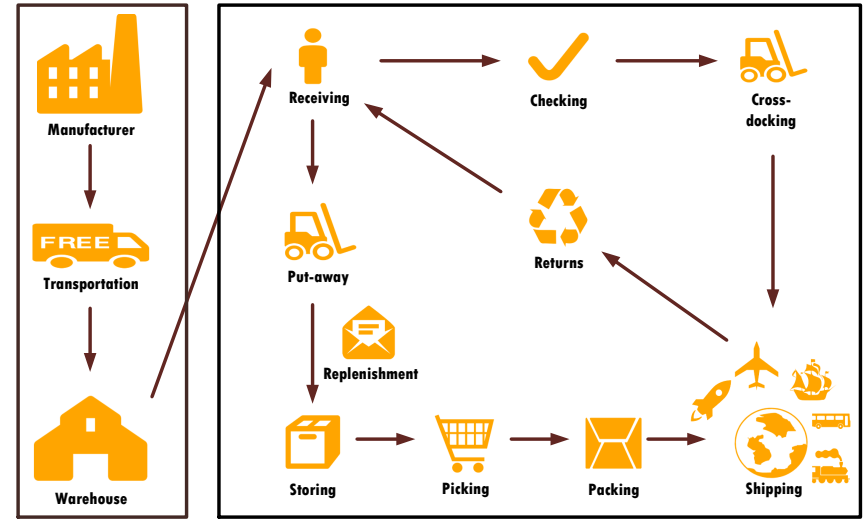

Fig. 4. The Logistic Process Flow in Warehouse

The product is then accepted, marked e.g. by a bar code and registered in the information system, and staged for put away. The receiving process takes about $10 \%$ of operating costs [6]. The paper [36] discusses the role of goods receiving and shipping in warehouse environments. A formal notation of schedules is proposed and the specific analytical examples are shown in this paper.

Storing operations consist of the distribution of goods to storage areas (transportation to a storage place or crossdocking, which is the transportation directly to the shipping department), identification (if it was not done during acceptance), assignment of the storage bin and put-away which is a simple determination of a storage bin concerning the physical dimensions and the weight of goods; storage monitoring is also a part of management systems - to know which goods are available and where.

Put-away is a process which requires a strictly determined storage location. This is very important, because the information system has to know all the time what storage locations are available, what is the location of a specific type of goods and where each particular pallet is stored. This information is also used for an efficient design of a pick-list. This process requires about $15 \%$ [6] of operating costs, because this covers a lot of transfers from the gate to the storage place.

Picking (also called Retrieval) is a process which covers lots of issues. First, a pick-list is given to an employee. The picking takes about $55 \%$ of the warehouse operating costs [6] (according to [7] it is 50\% - 70\%) and consists of: Traveling (55\%), Searching (15\%), Extracting (10\%), and Paperwork $(20 \%)$. Picking can be of two types, homogeneous and heterogeneous. Homogeneous picking is quite simple, the picker operates simply with a whole pallet. In heterogeneous picking the picker is told where and what to pick, in what quantity and units. Due to customer needs, the heterogeneous picking is logically more frequent. The disadvantage of heterogeneous picking is that a smaller unit means higher costs. The pick-list is still quite often a sheet of paper, but in some warehouses the pickers use the smart embedded devices such as the Bar-Code Reader, Personal Digital Assistant etc. The advantage of using such equipment is reviewed in [37], [38].

The planning of the picking process is based on orders and supported by picker routing methods. Basic routing methods are described in [5]. Picking of goods can be done by many ways. The special case of picking is order-picking which is a consolidation of a customized quantity of one or more articles related to a specific order. Sharing of order-picking is also a quite frequent way of picking. The sharing of an order is very related to batching, grouping, and zoning. The order-picking was also designed by algorithm based on Traveling Salesman Problem (TSP) heuristics introduced in [39], which performs better for multiple picking than routing methods. In [40] it was discovered that appropriate sequencing of picking is one of the crucial factors to achieve a high efficiency of picking. Since the traveling is the most timeconsuming part of the process, the scientists paid attention mostly to this part of the problem.

The travel time is an increasing function of the travel distance, which was investigated in many papers and considered one of the primary optimization conditions. In [41] are described three analytical models of expected travel distance for return policy, traversal policy, and midpoint policy. To allay blocking and/or congestion, the order-picking strategies can be used, or the layout of the warehouse can be adjusted in the meaning of wide-aisles, or zoning can be applied [42]. The congestion has also been investigated in [7] by waiting time of a picker queuing to enter the warehouse. The analytical and simulation models of order-picking systems in [13] were developed to discover the system behavior with different activity levels. The result was that the congestion among workers can be a significant issue if the space is highly utilized. In [34] was provided an analytical approach for the expected system throughout time approximation. In [43] and [44] was determined a relationship between pick density and throughput, which has demonstrated the significance of blocking. Inasmuch as the models of picking are mostly investigated only as single-picker operations, and are consequently suitable to evaluate the order-picking efficiency by travel distance, an aisle congestion never takes place in such models. In real-world situations the congestion is a normal everyday situation in systems with multiple order-picking and dozens of workers. The throughput analysis for order-picking with multiple pickers and aisle congestion is investigated in [45] and [46]. In [47] were investigated heuristic methods and it was proved that the storage assignment policies in a multiple picker warehouse environment are outperformed by the proposed heuristics policies in this paper.

The batching in the narrow-aisle order-picking system with the picker blocking consideration was investigated in [48]. The paper has proposed strategies to control picker blocking with $5 \%-15 \%$ reduction in the total retrieval time. In [49] has been proposed an Ant Colony Optimization (ACO) routing algorithm for two order pickers with the consideration of congestions. The paper analyzes the warehouse layout and its impact on the order-picking system performance and proves the good performance in dealing with the congestions if two pickers are used simultaneously. In [50] has been proposed two new batch construction heuristics called K-means Batching and Self-Organization Map Batching which minimize the total travel distance and the average picking truck utility. 
Also the online version of the multiple picking agents for the warehouse management has been focused on in [51]. The rescheduling of the buffer of orders, to which new orders arrive randomly while old orders are being picked, was investigated and two real time algorithms were proposed. The solution performs good when dynamism is low or moderate, but when it is high, the solution tends to fail. The dynamic order-picking and cost reduction generated by optimal policies is discussed in [52]. This research used a Markov Decision Process based heuristics which is compared to some naive heuristics and an improvement in the range of $7 \%-99 \%$ is depicted. Other heuristic for online batching based on offline batching is introduced in [53] and [54]. The algorithms are evaluated in a series of experiments and it is shown that the choice of an appropriate batching method can lead to significant minimization of the maximum completion time. In [55] have been proposed $A^{*}$-algorithm for the routing and Simulated Annealing-algorithm for the batching. For batches of tree customers, the proposed algorithm produces results with an error of less than $1.2 \%$ compared to the optimal solution.

Consolidation of an order is a process of completion of a customer's order in case that it was picked by more than one pickers. The paper [56] has proposed the design and the operation of an order-consolidation warehouse. The paper provides a simulation model and shows its application. When the order is consolidated, the process of checking follows.

Checking of an order is a process that checks if the order is complete and accurate.

Packing ensures that the picked and consolidated goods, also checked for the completeness of an order, are packed for transportation and given to the shipping department. Packing can also be ensured by an autonomous packing department in the warehouse, then the consolidation and checking are usually part of this department.

Shipping ensures that the packed consignment is provided by transport destinations, assigned to the truck and optimally loaded on the truck. The shipping process is ensured by the shipping department that can also secure three preceding jobs.

Cross-docking is a process which minimizes the storage and order-picking time while the receiving and shipping operations are still allowed to a full extent. The basic idea is to transfer goods directly from the incoming to the outgoing department without any other warehouse operations in between. In [57] the problem was handled as a Vehicle Routing Problem. In [58] have been presented a solution developed for multiple delivery centers by many sub-optimizations of single centers based on Neighborhood Search and Tabu Search algorithms. The scheduling of trucks in the cross-docking system with five meta-heuristic algorithms (Genetic Algorithms, Simulated Annealing, Tabu Search, Electromagnetismlike Algorithm, Variable Neighborhood Search) with respect to minimization of the total operation time is described in [59]. The analytical models for pre-distribution cross-docking (on the side of a manufacturing company) and post-distribution cross-docking (on the side of warehousing company) proposed in [60] had been compared with a traditional distribution center system. Analytical results showed a pre-distribution crossdocking as a preferred solution for centers with shorter supply lead time and lower uncertainty of demand, but in general the preference depends highly on business environment [60].

\section{CONCLUSION}

The optimal operation of a warehouse is achieved when each customer is satisfied completely according to his order, in due time and when all warehouse and logistic processes are done in the shortest possible time, with minimal cost and optimal utilization of resources under dynamically changing conditions. The literature presented in this paper gives great ideas of warehousing optimization, but only some of them are really applied in real-world warehouses and used. The problem of warehouse layout lies mainly in the effective use of space so the typical rectangular warehouses with narrow-aisles are most utilized. There is also a critical pressure on effective utilization of equipment and labor and its minimal quantity in the warehouse, which can also save the costs significantly.

The dedicated assignment based on the frequency of manipulation with goods is broadly used, but some big and wellknown companies, e.g. Amazon, use the chaotic assignment system and it seems to be a good solution as well. The routing methods supporting order-picking and picking itself have been investigated for single picking tours, but the batching seems to be standard for many companies. Moreover, the most of the scientific papers do not take into account the real conditions as the blocking and congestion are, but there are dozens of workers working simultaneously in the real warehouse or multipleblock warehouse and the congestion or even a collision must be taken into account in everyday operation.

The result of this review of warehouse optimization is that the real-world conditions should be applied instead of their relaxation for the sake of application. The work can be shared by many more employees than two, which was mostly investigated in the papers. The idea of how to apply this optimization is to utilize the shop scheduling techniques combined with Vehicle Routing Problems solving techniques.

The shop scheduling techniques can be employed when the work is scheduled in the warehouse, even when the work must by scheduled dynamically. The machines in shop scheduling problem are represented in the warehouse by any equipment needed for each job, such as trucks driven by workers (forklift hand pallet truck, fork-lift low truck, fork-lift high truck), checking units (workers), packing units (workers with special equipment) and others. The operations in the warehouse, called jobs in the scheduling, represent a single assignment given to the worker by operational manager e.g. the employee has to unload a pallet from a lorry, go through the warehouse and store it on a shelf. The job is composed of sub-operations called tasks. A task represents a single operation of job, e.g. receiving, unloading, put-away, moving and storing etc. The tasks can be done by several workers. So, the job is spread in few machines working in sequence in the language of shop scheduling problems. Transports, moving and routing of trucks in warehouse could be inspired by Automated Guided Vehicles (AGV) techniques transformed from open space Vehicle Routing Problem (VRP) techniques to warehouse environment. Application of these methods could further reduce the blocking and congestions as well as collisions of trucks. 


\section{ACKNOWLEDGMENT}

This research work is funded by projects SIX CZ.1.05/2.1.00/03.0072.

\section{REFERENCES}

[1] M. T. Hompel and T. Schmidt, Warehouse Managmenet - Automation and Organisation of Warehouse and Order Picking Systems. SpringerVerlag Berlin Heidelberg, 2007, iSBN-13: 971-3-540-35218-1.

[2] J. Gu, M. Goetschalckx, and L. F. McGinnis, "Research on warehouse design and performance evaluation: A comprehensive review," European Journal of Operational Research, vol. 203, no. 3 , pp. 539-549, 2010. [Online]. Available: http://www.sciencedirect.com/ science/article/pii/S0377221709005219

[3] F. Caron, G. Marchet, and A. Perego, "Optimal layout in lowlevel picker-to-part systems," International Journal of Production Research, vol. 38, no. 1, pp. 101-117, 2000. [Online]. Available: http://www.tandfonline.com/doi/abs/10.1080/002075400189608

[4] K. J. Roodbergen and R. d. Koster, "Routing methods for warehouses with multiple cross aisles," International Journal of Production Research, vol. 39, no. 9, pp. 1865-1883, 2001. [Online]. Available: http://www.tandfonline.com/doi/abs/10.1080/00207540110028128

[5] - "Routing order pickers in a warehouse with a middle aisle," European Journal of Operational Research, vol. 133, no. 1, pp. 32-43, 2001. [Online]. Available: http://www.sciencedirect.com/science/article/ pii/S0377221700001776

[6] J. J. Bartholdi and S. T. Hackman, Warehouse \& Distribution Science. Georgia Institute of Technology, School of Industrial and Systems Engineering, The Supply Chain and Logistics Institute, August 22 2011, latest release: version 0.95

[7] R. d. Koster, T. Le-Duc, and K. J. Roodbergen, "Design and control of warehouse order picking: A literature review," European Journal of Operational Research, vol. 182, no. 2, pp. 481-501, 2007. [Online]. Available: http://www.sciencedirect.com/science/article/ pii/S0377221706006473

[8] S. S. Heragu, Facilities Design, 3rd ed. CRC Press, June 19 2008, iSBN-13: 978-1420066265.

[9] K. R. Gue and R. D. Meller, "Aisle configurations for unit-load warehouses," IIE Transactions, vol. 41, no. 3, pp. 171-182, 2009.

[10] L. M. Pohl, R. D. Meller, and K. R. Gue, "An analysis of dualcommand operations in common warehouse designs," Transportation Research Part E: Logistics and Transportation Review, vol. 45, no. 3, pp. 367-379, 2009. [Online]. Available: http://www.sciencedirect.com/ science/article/pii/S1366554508001191

[11] _ " "Optimizing fishbone aisles for dual-command operations in a warehouse," Naval Research Logistics, vol. 56, no. 5, pp. 389-403, 2009.

[12] K. R. Gue, G. Ivanovic̄, and R. D. Meller, "A unit-load warehouse with multiple pickup and deposit points and non-traditional aisles," Transportation Research Part E: Logistics and Transportation Review, vol. 48, no. 4, pp. 795-806, 2012. [Online]. Available: http: //www.sciencedirect.com/science/article/pii/S1366554512000117

[13] K. Gue, R. Meller, and J. Skufca, "The effects of pick density on order picking areas with narrow aisles," IIE Transactions, vol. 38, no. 10, pp. 859-868, 2006. [Online]. Available: http://www.scopus. com/inward/record.url?eid=2-s2.0-33746452243\&partnerID=40\&md5= f9fb583c292344e9560d0aa020e6e9ef

[14] M. Napolitano, "Real dc stories: Low cost deep impact," Logistics Management, vol. 48, no. 1, pp. 46-49, 2009.

[15] J. J. Bartholdi and L. K. Platzman, "Retrieval strategies for a carousel conveyor," IIE Transactions, vol. 18, no. 2, pp. 166-173, 1986. [Online]. Available: http://www.tandfonline.com/doi/abs/10.1080/ 07408178608975344

[16] J. B. Ghosh and C. E. Wells, "Optimal retrieval strategies for carousel conveyors," Mathematical and Computer Modelling, vol. 16, no. 10, pp. 59-70, 1992. [Online]. Available: http: //www.sciencedirect.com/science/article/pii/089571779290060X

[17] N. Litvak, "Optimal picking of large orders in carousel systems," Operations Research Letters, vol. 34, no. 2, pp. 219-227, 2006. [Online]. Available: http://www.sciencedirect.com/science/article/pii/ S0167637705000532

[18] J. P. V. D. Berg, "Multiple order-pick sequencing in a carousel system: A solvable case of the rural postman problem," The Journal of the Operational Research Society, vol. 47, no. 12, pp. 1504-1515, December 1996.
[19] R. G. Vickson and A. Fujimoto, "Optimal storage locations in a carousel storage and retrieval system," Location Science, vol. 4, no. 4, pp. 237-245, 1996. [Online]. Available: http: //www.sciencedirect.com/science/article/pii/S096683499700003X

[20] Y. A. Bozer and J. A. White, "Travel-time models for automated storage/retrieval systems," IIE Transactions, vol. 16, no. 4, pp. 329-338, 1984. [Online]. Available: http://www.tandfonline.com/doi/abs/10.1080/ 07408178408975252

[21] _ - "Design and performance models for end-of-aisle order picking systems," Management Science, vol. 36, no. 7, pp. 852-866, July 1990.

[22] Y.-H. Hu, S. Y. Huang, C. Chen, W.-J. Hsu, A. C. Toh, C. K. Loh, and T. Song, "Travel time analysis of a new automated storage and retrieval system," Computers \& Operations Research, vol. 32, no. 6, pp. 1515-1544, 2005. [Online]. Available: http://www.sciencedirect.com/science/article/pii/S0305054803003575

[23] T. Lerher, I. Potrē, M. Sraml, and T. Tollazzi, "Travel time models for automated warehouses with aisle transferring storage and retrieval machine," European Journal of Operational Research, vol. 205, no. 3, pp. 571-583, 2010. [Online]. Available: http: //www.sciencedirect.com/science/article/pii/S0377221710000330

[24] B. R. Sarker and P. S. Babu, "Travel time models in automated storage/retrieval systems: A critical review," International Journal of Production Economics, vol. 40, no. 2-3, pp. 173-184, August 1995. [Online]. Available: http://www.sciencedirect.com/science/article/ pii/0925527395000752

[25] J. P. V. D. Berg, "Analytic expressions for the optimal dwell point in an automated storage/retrieval system," International Journal of Production Economics, vol. 76, no. 1, pp. 13-25, 2002. [Online]. Available: http://www.sciencedirect.com/science/article/pii/S0925527301001499

[26] I. Potrē, T. Lerher, J. Kramberger, and M. Sraml, "Simulation model of multi-shuttle automated storage and retrieval systems," Journal of Materials Processing Technology, vol. 157-158, no. 0, pp. 236-244, 2004. [Online]. Available: http://www.sciencedirect.com/science/article/ pii/S0924013604010787

[27] J. L. Haskett, "Cube-per-order index - a key to warehouse stock location," Transportation and Distribution Management, vol. 3, no. 1, pp. 27-31, 1963.

[28] C. G. Petersen, "An evaluation of order picking routeing policies," International Journal of Operations \& Production Management, vol. 17, no. 11, pp. 1098-1111, 1997.

[29] H. Brynzer and M. I. Johansson, "Storage location assignment: Using the product structure to reduce order picking times," International Journal of Production Economics, vol. 46, no. 1, pp. 595603, December 1996. [Online]. Available: http://ideas.repec.org/a/eee/ proeco/v46-47y1996ilp595-603.html

[30] R. J. Mantel, P. C. Schuur, and S. S. Heragu, "Order oriented slotting: A new assignment strategy for warehouses," European Journal of Industrial Engineering, vol. 1, no. 3, pp. 301-316, January 1 2007. [Online]. Available: http://inderscience.metapress.com/content/ A262442816131833

[31] H. D. Ratliff and A. S. Rosenthal, "Order-picking in a rectangular warehouse: A solvable case of the traveling salesman problem," Operations Research, vol. 31, no. 3, pp. 507-521, May-June 1983.

[32] G. Clarke and J. Wright, "Scheduling of vehicles from a central depot to a number of delivery points," Operations Research, vol. 12, no. 4, pp. 568-581, 1964.

[33] R. d. Koster, E. S. V. d. Poort, and M. Woltersa, "Efficient orderbatching methods in warehouses," International Journal of Production Research, vol. 37, no. 7, pp. 1479-1504, 1999

[34] I. V. Nieuwenhuyse and R. B. d. Koster, "Evaluating order throughput time in 2-block warehouses with time window batching," International Journal of Production Economics, vol. 121, no. 2, pp. 654-664, 2009. [Online]. Available: http://www.sciencedirect.com/science/article/ pii/S0925527309000723

[35] H. d. Ruijter, "Improved storage in a book warehouse," Master's thesis, University of Twente, Enschede - The Netherlands, October 2007.

[36] T. Ambroziak and K. Lewczuk, "A method for scheduling the goods receiving process in warehouse facilities," Total Logistic Management, vol. 5, no. 1, pp. 7-14, 2008.

[37] X. Zhu, S. K. Mukhopadhyay, and H. Kurata, "A review of rfid technology and its managerial applications in different industries," Journal of Engineering and Technology Management, vol. 29, no. 1, pp. 152-167, 2012. [Online]. Available: http://www.sciencedirect.com/ science/article/pii/S092347481100049X

[38] M. K. Lim, W. Bahr, and S. C. H. Leung, "Rfid in the warehouse: A literature analysis (1995-2010) of its applications, benefits, challenges and future trends," International Journal of Production 
Economics, vol. 145, no. 1, pp. 409-430, 2013. [Online]. Available: http://www.sciencedirect.com/science/article/pii/S0925527313002314

[39] C. Theys, O. Braysy, W. Dullaert, and B. Raa, "Using a tsp heuristic for routing order pickers in warehouses," European Journal of Operational Research, vol. 200, no. 3, pp. 755-763, 2010. [Online]. Available: http://www.sciencedirect.com/science/article/pii/S0377221709000514

[40] K. Moeller, "Increasing warehouse order picking performance by sequence optimization," Procedia - Social and Behavioral Sciences, vol. 20, no. 0, pp. 177-185, 2011. [Online]. Available: http: //www.sciencedirect.com/science/article/pii/S1877042811014030

[41] H. Hwang, Y. Oh, and Y. Lee, "An evaluation of routing policies for order-picking operations in low-level picker-to-part system," International Journal of Production Research, vol. 42, no. 18, pp. 3873-3889, 2004. [Online]. Available: http://www.scopus. com/inward/record.url?eid=2-s2.0-4944240916\&partnerID=40\&md5= 73cb6af28941f0e4ab9ea72f412233e1

[42] M. B. M. d. Koster and M. Yu, "Minimizing makespan and throughput times at aalsmeer flower auction," Journal of Operational Research Society, vol. 59, no. 9, pp. 1182-1190, September 2008. [Online]. Available: http://dx.doi.org/10.1057/palgrave.jors.2602474

[43] S. Hong, A. L. Johnson, and B. A. Peters, "Analysis of picker blocking in narrow-aisle batch picking," in Proceedings of 2010 International Material Handling Research Colloquium (IMHRC), K. Ellis, K. Gue, d. R. Koster, R. Meller, B. Montreuil, and M. Oglep, Eds. The Material Handling Institue, Charlotte, NC, USA, 2010.

[44] P. J. Parikh and R. D. Meller, "A note on worker blocking in narrow-aisle order picking systems when pick time is non-deterministic," IIE Transactions, vol. 42, no. 6, pp. 392-404, 2010. [Online]. Available: http://www.scopus.com/ inward/record.url?eid=2-s2.0-77951121237\&partnerID=40\&md5= 6d6f6b92c672c42e12c419901b3428af

[45] J. C.-H. Pan and P.-H. Shih, "Evaluation of the throughput of a multiple-picker order picking system with congestion consideration," Computers \& Industrial Engineering, vol. 55, no. 2, pp. 379-389, 2008. [Online]. Available: http://www.sciencedirect.com/science/article/ pii/S036083520800003X

[46] J. C.-H. Pan and M.-H. Wu, "Throughput analysis for order picking system with multiple pickers and aisle congestion considerations," Computers \& Operations Research, vol. 39, no. 7, pp. 1661-1672, 2012. [Online]. Available: http://www.sciencedirect.com/science/article/ pii/S0305054811002838

[47] J. C.-H. Pan, P.-H. Shih, and M.-H. Wu, "Storage assignment problem with travel distance and blocking considerations for a picker-topart order picking system," Computers \& Industrial Engineering, vol. 62, no. 2, pp. 527-535, 2012. [Online]. Available: http: //www.sciencedirect.com/science/article/pii/S036083521100324X

[48] S. Hong, A. L. Johnson, and B. A. Peters, "Batch picking in narrow-aisle order picking systems with consideration for picker blocking," European Journal of Operational Research, vol. 221, no. 3 , pp. 557-570, 2012. [Online]. Available: http://www.sciencedirect.com/ science/article/pii/S0377221712002706

[49] F. Chen, H. Wang, C. Qi, and Y. Xie, "An ant colony optimization routing algorithm for two order pickers with congestion consideration," Computers \& Industrial Engineering, vol. 66, no. 1, pp. 77-85, 2013.

[50] L.-F. Hsieh and Y.-C. Huang, "New batch construction heuristics to optimise the performance of order picking systems," International Journal of Production Economics, vol. 131, no. 2, pp. 618-630, 2011. [Online]. Available: http://EconPapers.repec.org/RePEc:eee:proeco:v: 131:y:2011:i:2:p:618-630

[51] J. I. U. Rubrico, T. Higashi, H. Tamura, and J. Ota, "Online rescheduling of multiple picking agents for warehouse management," Robot. Comput.-Integr. Manuf., vol. 27, no. 1, pp. 62-71, February 2011. [Online]. Available: http://dx.doi.org/10.1016/j.rcim.2010.06.011

[52] Y. Bukchin, E. Khmelnitsky, and P. Yakuel, "Optimizing a dynamic order-picking process," European Journal of Operational Research, vol. 219, no. 2, pp. 335-346, 2012. [Online]. Available: http: //www.sciencedirect.com/science/article/pii/S0377221711011350

[53] S. Henn, "Algorithms for on-line order batching in an order picking warehouse," Computers \& Operations Research, vol. 39, no. 11, pp. 2549-2563, 2012. [Online]. Available: http://www.sciencedirect.com/ science/article/pii/S0305054812000020

[54] S. Henn and V. Schmid, "Metaheuristics for order batching and sequencing in manual order picking systems," Computers \& Industrial Engineering, vol. 66, no. 2, pp. 338-351, 2013, iSSN: 03608352. [Online]. Available: http://www.sciencedirect.com/science/article/ pii/S0360835213002015
[55] M. Matusiak, R. Koster, L. Kroon, and J. Saarinen, "A fast simulated annealing method for batching precedence-constrained customer orders in a warehouse," European Journal of Operational Research, vol. ?, no. ?, p. ?, 2013. [Online]. Available: http: //www.sciencedirect.com/science/article/pii/S0377221713004670

[56] A. E. Gray, U. S. Karmarkar, and A. Seidmann, "Design and operation of an order-consolidation warehouse: Models and application," European Journal of Operational Research, vol. 58, pp. 14-36, 1992.

[57] G. Mosheiov, "Vehicle routing with pick-up and delivery: Tourpartitioning heuristics," Computers and Industrial Engineering, vol. 34, no. 3, pp. 669-684, 1998.

[58] G. Barbarosoglu and D. Ozgur, "A tabu search algorithm for the vehicle routing problem," Computers and Operations Research, vol. 26, no. 3, pp. 255-270, 1999. [Online]. Available: http://www.scopus. com/inward/record.url?eid=2-s2.0-0033102291\&partnerID=40\&md5= f165e5689ada1c5df72d37d8aaffa60b

[59] B. Vahdani and M. Zandieh, "Scheduling trucks in cross-docking systems: Robust meta-heuristics," Computers \& Industrial Engineering, vol. 58, no. 1, pp. 12-24, 2010. [Online]. Available: http://www. sciencedirect.com/science/article/pii/S0360835209001776

[60] H. Yan and S.-1. Tang, "Pre-distribution and post-distribution crossdocking operations," Transportation Research Part E: Logistics and Transportation Review, vol. 45, no. 6, pp. 843-859, 2009. [Online]. Available: http://www.sciencedirect.com/science/article/pii/ S1366554509000830

Jan Karásek received MSc degree in Telecommunications and Informatics in 2009 and MSc degree in Corporate Management and Economics in 2010 from the Brno University of Technology, Czech Republic. Currently, he is a PhD candidate at the Department of Telecommunications at the same university. The theme of his PhD thesis is the Optimization of Distributed Processes Using Evolutionary Algorithms. At the same time, he is employed with the Department of Telecommunications as a project manager and he is also involved in teaching of Theoretical Informatics. His research interests include: artificial intelligence, machine learning, evolutionary computation techniques, process optimization and automation, genetic algorithms \& genetic programming and their realworld application, and parallel programming. 